\title{
English Vocabulary Teaching from a Cognitive Perspective
}

\author{
Yun Chang*, Bingyu Li, Junqing Lu \\ Foreign Language College, Inner Mongolia Agricultural University, Hohhot, China \\ Email: *cy4684510@126.com
}

How to cite this paper: Chang, Y., Li, B.Y., and Lu, J.Q. (2021) English Vocabulary Teaching from a Cognitive Perspective. Open Access Library Journal, 8: e7777. https://doi.org/10.4236/oalib.1107777

Received: July 20, 2021

Accepted: September 4, 2021

Published: September 7, 2021

Copyright $\odot 2021$ by author(s) and Open Access Library Inc.

This work is licensed under the Creative Commons Attribution International License (CC BY 4.0).

http://creativecommons.org/licenses/by/4.0/

\section{(c) (i) Open Access}

\begin{abstract}
As a higher cognitive function of the human brain, language development is inextricably linked to brain cognition. Cognitive research provides a theoretical basis and methodology for language development and learning. Three meta-linguistic cognitive factors, phonological-orthographic and morphological awareness, are effective predictor variables and important influencing factors for vocabulary learning and further literacy development. A view of vocabulary learning based on cognitive linguistic theory can effectively change English teaching practice.
\end{abstract}

\section{Subject Areas}

Linguistics

\section{Keywords}

Vocabulary Learning, Phonological Awareness, Morphological Awareness

\section{Introduction}

Vocabulary learning has always been one of the key points of English teaching in China. The new English standard stipulates that 3500 words and $400-500$ phrases should be mastered for high school graduation [1]; the Syllabus of College English stipulates that students must "master 4000 words and a certain amount of common phrases in a comprehension style, among which 2500 words are to be mastered in a reuse style" in order to reach CET4. At the same time, in July 2007, the Ministry of Education revised the Teaching Requirements for College English Courses again, putting forward new requirements for English vocabulary teaching from three levels, namely general requirements, higher requirements and higher requirements. Among the general requirements, students 
are required to "master a vocabulary of about 4795 words and 700 phrases, of which about 2000 words are active vocabulary. That is to say students are required to use these vocabularies proficiently in both oral and written expressions on a cognitive basis" [2]. It can be seen that students should be acquainted with basic English vocabulary knowledge and develop certain vocabulary learning methods and skills in junior high school, and even in elementary school, it will lay a solid foundation for every higher level of English learning.

Overseas research on second language vocabulary acquisition (especially on vocabulary quantity) has long achieved impressive results. English teachers in China have also realized the importance of vocabulary teaching in recent years and have actively carried out studies related to vocabulary learning, such as vocabulary size, vocabulary memory, and vocabulary learning strategies. However, in the specific teaching practice, we find that some schools do not require students to memorize words, or even develop students to spell words, not to mention the training of learning methods at the elementary school level. However, at the junior and senior high school level, teachers think that the problems about vocabulary learning and training would have been solved; they don't think they are obliged to focus on the teaching and the enlargement of the students' vocabulary. Therefore, vocabulary learning and teaching falls into a state of kicking the ball, resulting in the consequences of not only a small vocabulary of students; the bigger problem is that students have lost the best time to acquire vocabulary learning. Vocabulary learning thus becomes a perpetual headache for students, who have no way to cope with the college entrance exams or CET4 and CET6. From the perspective of cognitive psychology, it is of great theoretical and practical significance to explore the cognitive developmental rules and characteristics that are consistent with students' English vocabulary learning, to improve learners' comprehensibility, memorability and productivity of English vocabulary, and thus to improve learners' vocabulary learning ability.

\section{The Relationship between Cognition and Language}

American psychologist Holston summarized five representative definitions of cognition [3]: cognition is information processing; cognition is mental symbolic operations; cognition is problem solving; cognition is thinking; cognition is a set of related activities, such as: perception, thinking, memory, judgment, reasoning, learning, imagination, language, etc. From his point of view, language and cognition are inseparable, and the study of language is bound to involve cognitive problems. Different psychologists have different views on the relationship between language and cognition, which can be roughly divided into two categories: one, language determines cognition. Wolfe puts forward the hypothesis of language relativity and language absoluteness, believing that language determines cognition, different languages, different cognitive activities, and people's cognition of the objective world is carried out through language. Second, cognition determines language. Piaget believed that before children mastered language, 
they relied on action or internalized action-arithmetic to think, indicating that the source of children's cognition is not language but action, but as children develop, language and cognition are closely linked together again. In recent years, Vygotsky's socio-cultural-historical perspective has gained increasing attention and recognition in the field of child development. Vygotsky believed that language is very important in the process of cognitive change and that the acquisition of language skills is the most important achievement in a child's development. The linguistic symbol system contains the results of innumerable human schemata and formalizations of linguistic situations, and children actually "inherit" these results when they acquire linguistic symbols in social communication. Children acquire language as a result of their cognitive development and socio-cultural-historical processes.

We are using language every day, while many people are studying language as a scientific research area. The disciplines that study language are linguistics, psychology, cognitive psychology, and sociolinguistics. The cognitive study of language intersects with psycholinguistics, a cross-pollination of linguistics and cognitive psychology, and cognitive neuroscience. In the past century, the field of language cognition has developed a solid foundation and has been sufficiently developed. The cognitive study of language is not only a study of the production and development of children's native language and the discovery of patterns of language acquisition in children, but also a study of the learning and acquisition of second languages, providing a theoretical basis for second language learning and teaching. Examining language acquisition and learning from a cognitive perspective has led us to discover that. On the one hand, cognition (thinking) is the basis for language development. Children's mastery of various word categories develops step by step from the concrete to the abstract. The reason for this development is that children's cognition is gradually refined from concrete to abstract. From our study of children's initial vocabulary acquisition process, we also found that if subjects have a higher level of cognitive development, they will have a higher level of language development, indicating that cognitive development is the cornerstone of children's language development. On the other hand, abstract thinking is carried out through the tool of highly abstract language, and it can be argued that without highly generalized language, humans cannot have highly generalized thinking. It follows that the relationship between language and cognition cannot simply be described as one in which cognition determines language or language determines cognition. The relationship between cognitive development and language development is bidirectional, dialectical, and interacts in a complex way.

\section{The Cognitive Psychological Basis of Vocabulary Learning}

Vocabulary acquisition in both native and second languages is a lifelong cognitive process, and acquiring a sufficient amount of vocabulary is a central issue in language development. Researchers have found that children's language devel- 
opment is closely related to the following meta-linguistic cognitive factors, namely phonological-orthographic and morphological awareness. The development of phonological-orthographic processing skills promotes the learner's ability to discriminate phonology and to improve the speed and accuracy of transcribing phonological streams to complete the processing of semantic meaning. If learners can efficiently manipulate phonological awareness units, they can quickly decode a word input (sound stimuli, visual stimuli) from the syllable to the phonemic level, extract the semantic meaning of this word from the mental lexicon, and complete the processing of language. When learning a new word, learners can also take advantage of this sound-form consistency rule to reduce the cognitive resources invested in memorizing the word, so that they can know the pronunciation of a word when they see it and spell it when they can read it, thus realizing the trinity of storing the sound, form and meaning of a word.

Another major characteristic of English is that it represents both phonemes and morphemes. Morpheme awareness refers to the learner's ability to perceive and manipulate knowledge of the structure of lexical morphemes, i.e., the child's ability to realize that English vocabulary is mostly roots plus affixes or root plus root combinations. By decomposing and combining the structural components of lexical morphemes, the meaning of words can be guessed, decoding speed can be accelerated, and semantic extraction can be accomplished successfully [4]. At the same time, grammatical features of morphemes and family features of morphemes can promote rapid growth of learners' vocabulary, both of which are primary prerequisites for the development of reading comprehension skills. The development of spelling ability is also facilitated by morpheme awareness, and the combination of roots plus affixes enables learners to acquire spelling rules for multilingual words and save cognitive resources. The above is about the role of morpheme awareness on language output ability. On the role of input to language, morpheme awareness can help learners cognitively process and store words from the word block (lexical block) level, which saves cognitive resources and improves memory efficiency as well. There are a large number of multilingual words in English, and many words are derived from a single root word. Therefore, storing and memorizing words in the way of vocabulary families, rather than individual words, is not only conducive to expanding vocabulary, but more importantly, this intrinsic connection between words is conducive to strengthening the breadth and depth of vocabulary memory, and more easily contributes to word extraction.

The phonological and morphological features of English are the basis and prerequisite for developing children's phonological and morphological awareness, and the development of phonological-orthographic and morphological awareness is a sufficient condition for the development of learners' literacy skills. At the same time, intervention training on this basis has been shown to contribute to phonological and morphological awareness both for native English learners and for second learners to expand their English vocabulary and improve 
their literacy skills.

\section{The Recommendations for Teaching English Vocabulary}

At present, the study of vocabulary acquisition theory has become one of the important research areas in the field of applied linguistics abroad. The modern research in the sense of "vocabulary acquisition: a neglected aspect of language learning" was published by the British psycholinguist P. Meara. Since then, other linguists have been studying vocabulary learning, especially with the development of cognitive neuroscience, and researchers have been revisiting specific vocabulary learning and teaching issues from the cognitive symbolic processing perspective of language learning.

Combining the lexical composition characteristics of different language systems and the cognitive development characteristics of learners at different ages, the recommendations for teaching English vocabulary include the following aspects.

First, vocabulary learning early emphasizes the cultivation and training of phonological awareness. English belongs to the phonetic writing system, and the composition and representation of language is based on phonetics in the first place, so mastering the rule of phonetic-form correspondence is the basis for the development of learners' early literacy skills. If one becomes aware of this rule earlier and establishes a correspondence between sound stimuli and the representation of this sound in the brain, one can use this rule to operate, thus facilitating the encoding and decoding of words and promoting the improvement of reading and spelling skills.

Phonological awareness training takes as its entry point the manipulation of three phonological awareness units: syllable, initial-rhyme, and phonemic position, to promote learners' ability to discriminate English phonology and to improve the speed and accuracy of transcribing the phonological stream to complete the processing of semantics. If learners can efficiently manipulate these three phonological awareness units, they can quickly decode a word input (sound stimuli, visual stimuli) from syllable to phonemic level, extract the semantic meaning of this word from the mental lexicon, and complete the processing of language. When learning a new word, learners can also use this phonological consistency rule to reduce the investment of cognitive resources in memorizing the word, so that they can know the pronunciation of a word when they see it, and can spell it when they can read it, thus achieving storage of the sound, form, and meaning of the word. The development of reading comprehension ability is based on the development of word decoding ability. If you can quickly identify words and complete the decoding of words when reading at the discourse level, it is conducive to improving the speed and accuracy of reading comprehension. Chang Yun (2014) through to four, six grade Chinese learners of English phonetics, morpheme awareness-before the test after the training-measuring contrast research, the results show that English phonetics, morpheme awareness 
training on English words semantic identification, spelling has effect, and, in the young period of English phonetic consciousness training on understanding and vocabulary memory effect is significantly higher than the effect of the training of words. It shows that phonological awareness training can promote the development of spelling to a certain extent.

Second, the middle and high levels carry out and promote the study of phonological awareness training. English language writing system is not only based on phonetics, but also has phonological features. Foreign research on the role of morpheme awareness on reading and writing ability has nearly 40 years of history, China's researchers are also early aware of the morpheme structure characteristics, from the point of view of the construction of the lexical approach to study the role of this feature of the English vocabulary on learners' vocabulary expansion and reading and writing ability. Morpheme knowledge is also related to vocabulary knowledge and reading comprehension, and at different stages learners encounter increasingly morpheme-complex vocabulary in which most of the meaning can be obtained through morpheme processing. Morpheme processing involves two most basic competencies: segmentation, i.e., the identification of the morphemic components of words through systematic lexical structure analysis, and integration, i.e., the integration of segmented morphemic information. The role of knowledge of morpheme structure for lexical recognition has been demonstrated in many studies by using various research tools and methods, one of which comes from the word frequency effect, where the more frequently used words are more easily recognized. The analysis of lexical morpheme structure can lead to fluency in the recognition of long words. The other comes from priming experiments, where morpheme-associated words consist of the same root with different affixes, and previous studies have found that previously presented morpheme-associated words have a facilitative effect on subsequently appearing morpheme-associated words, such as "pain-paint, pain-pained" [5] [6]. The two processing abilities of morphemes are not exactly the same as phonological processing abilities; learners infer the meaning of words by decomposing their structural components [7], so the decomposition and combination of words can help learners understand and learn these words. For example, Liu Yunying (2008) investigated the relationship between Chinese children's English morpheme awareness and English vocabulary and English reading, and found that English morpheme awareness can continuously improve students' ability to predict word meaning and enlarge vocabulary, as well as their ability to recognize and read [8].

\section{Conclusions}

The importance of vocabulary is self-evident, both for native English acquisition and for second language learning. Learners' vocabulary ability is an integral part of language communication ability, and the size of vocabulary is a measure of a learner's foreign language proficiency. The following problems still exist in English vocabulary teaching in China: First, many English teachers lack research on 
systematic vocabulary teaching theories and vocabulary teaching strategies. In English teaching, teachers spend a lot of time explaining the new vocabulary of each unit, but the teaching effect is not good, and they cannot scientifically help learners to do effective vocabulary learning. Secondly, learners have not yet formed a correct view of language learning. They think that vocabulary learning is mechanical memorization and tend to spend a lot of time on memorizing vocabulary lists instead of starting from the language itself and discovering the phonological and morphological features inherent in English vocabulary itself, so as to learn vocabulary in a highly efficient way.

In our English vocabulary teaching, we should emphasize the vocabulary teaching strategy based on phonological awareness. This is manifested in the following aspects: 1) Teachers should analyze vocabulary, especially complex vocabulary, in terms of structure, so that students can acquire a certain number of affixes, roots, and knowledge of word formation and improve their sensitivity to knowledge of morphemic structure. 2) When learners develop initial morphemic awareness and encounter unfamiliar vocabulary, they are required to make inferences and guesses based on the individual components obtained from the analysis of 3 . In terms of accurate vocabulary use and vocabulary memory, learners are guided to learn the internal structure of English vocabulary from a morphological perspective by acquiring knowledge of morpheme structure and understanding the characteristics of morpheme constructions, thus helping learners to learn vocabulary quickly and efficiently and to expand their vocabulary.

Luckily, nowadays we have found more and more vocabulary books were compiled by the rule of the rules and characteristics of the word formation and structure, for example, Cet-4 Vocabulary: Word root + Associative memory Method from New Oriental Group. Moreover, we can search online for more vocabulary training course based on the methods of morpheme awareness training.

\section{Funding}

The paper as "The Western China Project of National Social Science Fund in 2016, Interlingual Influence of Mongolian Native Speakers in Trilingual Acquisition under Multicultural Background (Grant No.:16xyy018)", and Agricultural University Humanities and Social Science Research Subject "To promote cross-border research on the Mongolian language and culture in the Grassland Silk Road strategic objectives (Grant No.: XSK 201612)" part of the research results.

\section{Conflicts of Interest}

The authors declare no conflicts of interest.

\section{References}

[1] The Ministry of Education of the Republic of China (2011) English Curriculum 
Standards. Beijing Normal University Press, Beijing.

[2] Wen, Q. (2009) New Standards College English. Foreign Language Teaching and Research Press, Beijing.

[3] Chang, Y. and Wu, J. (2013) The Role of Metalinguistic Awareness on Second Language Literacy: Evidence from Training Studies: Evidence from Training Studies. Journal of Inner Mongolia Normal University (Education and Science), No. 12, 123-125.

[4] Zhao, Y. (1998) Cognitive Development and Metaphor. Foreign Languages and Foreign Language Teaching, No. 10, 8-10.

[5] Bruck, M. and Waters, G.S. (1990) An Analysis of the Component Spelling and Reading Skills of Good Readers-Good Spellers, Good Readers-Poor Spellers, and Poor Readers-Poor Spellers. In: Carr, T.H. and Levy, B.A., Eds., Reading and Its Development, Academic Press, San Diego, 161-206.

[6] Feldman, L.B. and Andjelkovic, D. (1992) Morphological Analysis in Word Recognition. In: Katz, L. and Frost, R., Eds., Orthography, Phonology, Morphology, and Meaning: An Overview, Lawrence Erlbaum Associates, Hillsdale, NJ, 103-105.

[7] Fowler, A.E. and Liberman, I.Y. (1995) The Role of Phonology and Orthography in Morphological Awareness. In: Feldman, L., Ed., Morphological Aspects of Language Processing, Erlbaum, Hillsdale, NJ, 189-209.

[8] Liu, Y. (2008) A Study on the Structure, Relationship and Function of Chinese and English Morpheme Awareness in Chinese Children's Reading. Beijing Normal University, Beijing. 